\title{
Choosing Whether to Lead, Lag, or Match the Market
}

\author{
Michael C. Sturman, Cornell University \\ David McCabe
}

This paper demonstrates how cost-benefit analysis can be used to develop a company's pay strategy. Using the case of Punk's Backyard Grill, a new venture starting in the Washington, DC area, quantitative aspects of Utility Analysis are combined with the judgments of the company's owners to provide estimates of the value associated with seven pay strategies. Results showed that leading the market by 5\% produced the greatest return. Sensitivity analysis is used to see how drastically estimates changes owing to the nature of the paper's estimates. This methods presented in this paper should help others making pay policy decisions use cost-benefit analysis as part of their decision process.

Compensation is a recurring issue in the hospitality industry. It has been shown that pay in hospitality is lower than in other industry, both for the service industry overall (Bureau of Labor Statistics, 2005) and even when controlling for the level of human capital of its workers (Sturman, 2001). At the same time, research is repeatedly showing that pay practices can affect organizational performance, for both a wide variety of industries (Brown, Sturman, \& Simmering, 2003) and the hospitality industry specifically (Maister, 2001; Peterson \& Luthans, 2006). And yet, practitioners are still faced with the ever practical decision of, "What should we do?"

This paper addresses this question for the particularly salient case of setting pay for a new company. While for many companies, pay and pay systems change incrementally over time, and thus a clear strategy may be hard to identify and modify, new start-ups must make determinations of pay and have the opportunity to establish and implement a clear pay policy. Furthermore, start-ups must face this decision, as they start with no employees and grow to become a new firm. They must choose a pay policy, whether that is matching the market (i.e., paying the average level for similar jobs in the labor market), leading the market (i.e., paying above the average), or lagging the market (i.e., paying below the average). Furthermore, whether leading or lagging, firms must decide the extent to which they deviate from the average. The purpose of this paper is to employ cost-benefit analysis to demonstrate 
how a company can use a structured process to determine the best pay strategy to implement. This paper uses the case of an entrepreneurial restaurant venture that is in the process of, among other activities, setting up its pay structure.

The textbook answer to choosing a pay policy is simple. The pay policy must (1) maximize the company's ability to attract and retain qualified employees, (2) be within the company's ability to pay, and (3) must be competitive in the marketplace (Anthony, Perrewe, \& Kacmar, 1993). The process entails setting the company's pay strategy, collecting market data, and then determining pay ranges (Milkovich \& Newman, 2005). Yet while the general process is clear, research has provided little guidance as to what specific pay policy should be chosen, and how to translate this into actual pay recommendations.

Cost-benefit analysis, and specifically Utility Analysis (Sturman, 2003), provides a tool to help make a specific recommendation in this regard. Utility analysis has been applied to compensation decision before (e.g., Klass \& McClendon, 1996; Sturman, Trevor, Boudreau, \& Gerhart, 2003), with the results showing that specific recommendations depend on characteristics of the situation being examined. To a large extent, pay recommendations hinge on the extent to which the company values employee performance and the direct costs of the pay system. This tool is applied for a specific case with two purposes in mind: (1) To demonstrate how utility analysis can be used to make a pay policy determination for a specific start-up restaurant; and (2) To provide a model so that others can use this tool applied to their own specific circumstance to make their own pay determinations.

\section{The Case of Punk's Backyard Grill}

As noted above, utility analysis has shown that the value of specific human resource interventions depends on characteristics of the specific context (Sturman, 2000). This paper applies utility analysis using the case of Punk's Backyard Grill. But before launching into the analyses, some background is needed to provide a context for the parameter choices and so that the reader understands this specific circumstance.

Punk's Backyard Grill is a fast-casual restaurant concept based on the familiar backyard grill gathering. With a comfortable interior décor evocative of the backyard cookout-picnic-style tables, redwood-style decking, an open grill area, and white picket fencing-Punk's Backyard Grill is designed to re-create, in a fast-casual restaurant environment, the nostalgic American backyard grill gathering. The menu will include items such as beef brisket, grilled chicken, spicy hot links, grilled fish and shrimp, fresh-ground Niman-Ranch hamburgers, unique entrée salads, homemade side orders, and fresh-baked 
deserts. The average check is expected to be around $\$ 10.00$. To be faithful to a true backyard cookout, there will be beer and wine-but no fryers-at Punk's Backyard Grill.

The founders have already integrated into their business plan an expansion strategy. They intend to open a second unit approximately 12 months after the opening of the first, and intend to build the first five units all within the Washington, DC Metropolitan area. This means that the main focus will be on building a brand and preparing for growth. To build a brand and open multiple units in one metropolitan area, the company feels that it needs to build a positive reputation as an employer of choice, remain profitable to help fund multiple units, and find ways to retain employees. As pay levels have often been found to be positively related to the size of the labor pool (Holzer, 1990; Krueger, 1988; Rynes \& Barber, 1990; Gerhart \& Milkovich, 1992), to be negatively related to turnover (Campbell, 1993; Heneman \& Judge, 2000), to allow organizations to be more selective when hiring (Milkovich \& Newman, 2005; Williams \& Dreher, 1992), and to increase overall efficiency (Brown et al., 2003), there are likely a significant number of benefits associated with providing higher pay levels. On the other hand, they need to keep costs under control and elicit all potential benefit from the investments in their employees. Thus, attempting to quantify the benefits and costs associated with various pay strategies appeared to be a potentially fruitful approach for designing the new pay system.

\section{Implementing the Cost Benefit Analysis}

This paper uses the tool of utility analysis to implement the cost-benefit analysis of various pay strategies. Utility analysis (described in depth in Sturman, 2003), essentially entails estimating the quantity of people effected, the extent to which performance changes because of a human resource intervention, the value associated with performance changes, and the costs associated with implementing the human resource intervention (see also Boudreau \& Berger, 1985). Utility analysis is implemented in steps, each described in detail below.

\section{Determining Costs}

When considering compensation, direct costs are relatively obvious- the amount paid to employees. This entailed determining what wage would be given to employees in each position, how many employees would be in each position, and how many hours each employee worked. Table 1 describes the positions, the number of anticipated hires, and the number of hours the owners expect the employees to work. Table 1 also described the spread of each pay range for each job (for more information on wage spreads and compensation system design, see Milkovich \& Newman, 2005). 
Pay levels were estimated through a combination of a pay survey for the Washington, DC area (Wage Watch, 2005) and various pay strategies. Then, using various pay strategies (from lag by $15 \%$ to lead by $15 \%$, in $5 \%$ increments), and assuming employees would be hired the minimum of the new pay range, total costs of each pay strategy were computed. Table 2 shows the total annual cost associated with each pay strategy. Lagging the market by $15 \%$ would have a direct wage cost of $\$ 395,897$; matching the market would cost $\$ 465,761$; leading the market by $15 \%$ would cost $\$ 535,625$.

TABLE 1. Position Information for Punk's Backyard Grill

\begin{tabular}{lcclcc}
\hline Position & $\begin{array}{c}\text { Number } \\
\text { in Position }\end{array}$ & $\begin{array}{c}\text { Expected } \\
\text { Hours of } \\
\text { Work } \\
\text { (Per Week) }\end{array}$ & $\begin{array}{c}\text { Market } \\
\text { Median Pay } \\
\mathbf{( \$ )}\end{array}$ & $\begin{array}{c}\text { Range } \\
\text { Spread } \\
(\%)\end{array}$ \\
\hline Assistant manager & 1 & 40 & Medium & 17.91 & 50 \\
BOH manager & 1 & 40 & Medium & 19.94 & 50 \\
Bus person & 2 & 35 & Low & 8.66 & 25 \\
Cashier & 6 & 25 & Low & 11.05 & 25 \\
FOH manager & 1 & 40 & Medium & 19.58 & 50 \\
Food runner & 2 & 35 & Low/Medium & 10.51 & 35 \\
Lead cook & 3 & 40 & Low/Medium & 14.49 & 35 \\
Line cook & 3 & 40 & Low/Medium & 12.60 & 35 \\
Prep cook & 3 & 30 & Low/Medium & 11.17 & 35 \\
Side server/Expo & 6 & 20 & Low/Medium & 11.23 & 35 \\
\hline
\end{tabular}

TABLE 2. Annual Total Cost and Effects for Various Pay Strategies

\begin{tabular}{lccc}
\hline Pay Strategy & $\begin{array}{c}\text { Annual Wage } \\
\text { Cost (\$) }\end{array}$ & $\begin{array}{c}\text { Applicants per } \\
\text { Position }\end{array}$ & $\begin{array}{c}\text { Effect on Job } \\
\text { Performance }\end{array}$ \\
\hline Lag $-15 \%$ & 395,897 & 2 & -0.100 \\
Lag $-10 \%$ & 419,185 & 3 & -0.067 \\
Lag $-5 \%$ & 442,473 & 4 & -0.033 \\
Match & 465,761 & 5 & 0.000 \\
Lead $+5 \%$ & 489,049 & 6 & 0.033 \\
Lead $+10 \%$ & 512,337 & 7 & 0.067 \\
Lead $+15 \%$ & 535,625 & 8 & 0.100 \\
\hline
\end{tabular}

\section{Determining Benefits}

Although direct costs are fairly straightforward to determine, benefits are harder to quantify. The largest issue is that utility analysis requires a number of estimates (Boudreau, 1991; Cascio, 2000; Sturman, 2000), many of which require data unavailable to a new start-up. On the other hand, one cannot ignore the question of determining wages. Thus, implementing the utility analysis tool would 
require the expertise of those opening Punk's Backyard Grill to provide those estimates. In part, as this paper is intended to demonstrate how utility analysis can be used to help make a pay strategy decision, in an academic sense the specific estimates are not important. Practitioners in other contexts can substitute values appropriate to their own situation. On the other hand, for practice, the estimates are critical to reach the optimal solution. Given this need, using expert-estimates, as opposed to empirically validated estimates, is somewhat questionable. On the other hand, empirical estimates cannot frequently be used, as the start-up does not have the experience to determine the affects associated with a pay policy, observe turnover levels, etc. Furthermore, although computations will be based on estimates, the alternative to deriving these estimates is simply to not conduct the utility analysis and instead approach the pay strategy question intuitively. Arguably, providing at least an attempt at quantification will help specify issues that must be considered, and can help lead to more profitable business decisions. The solution obtained through the cost-benefit analysis will be compared with common intuitive alternatives: Focus purely on cost, and thus lag the market by as much as possible (here, by $15 \%$ ), or avoid the decision by simply choosing to match the market.

The benefit portion of the utility analysis formula is computed as follows: Utility $=\left(\right.$ Number of Employees Affected $*$ Change in Performance $\left.* \mathrm{SD}_{\mathrm{y}}\right)-$ Cost

Where Change in Performance is how many standard deviations performance improves because of the pay policy, and SDy is the dollar value of a one standard deviation increase in job performance. The change in performance is a function of the number of applicants per position, the validity of the selection device, and the net gain in performance beyond selection caused by the pay policy (see Cascio, 2000 or Sturman, 2003).

For the analysis, the owners of the restaurant are planning to use a situational structured interview for each position. Past meta-analytical research has shown high validity for situational structured interview: McDaniel, Whetzel, Schmidt, and Maurer (1994) estimated a validity of 0.50; Taylor and Small (2002) estimated a validity of 0.45 . The slightly more conservative estimate of 0.45 is employed in the utility analysis implementation described here.

$\mathrm{SD}_{\mathrm{y}}$ is the value of an individual employee who performs one standard deviation above average. Often, this is expressed in terms of a percentage of salary. Forty percent is an often used conservative estimate (Boudreau, 1991; Hunter \& Schmidt, 1982; Schmidt, Hunter, Outerbridge, \& Trattner, 1986), although research has shown that SDy does increase with job complexity (Boudreau, 1991; Hunter, Schmidt, \& Judiesch, 1988). Thus, this paper employees the following assumptions: SDy equals $40 \%$ of 
salary for low complexity jobs (Bus Person and Cashier), 60\% for medium/low complexity jobs (food runner, lead cook, line cook, prep cook, and side server), and $80 \%$ for medium complexity jobs (assistant manager, $\mathrm{BOH}$ manager, and front of house manager).

The number of applicants per position, or more specifically the ability of the company to be selective, will depend on the pay policy. The more the company leads the market, the more they can be selective, both because of potentially more applicants per position and because fewer applicants will turn down offers of employment. The number of applicants per open position for each pay policy is also shown in Table 2. These estimates are based on the founders' knowledge of the Washington, DC labor market, local market research, and conversations with other restaurateurs. Additionally, higher compensation is associated with greater motivation, less shirking, and greater retention (Akerlof \& Yellen, 1986; Campbell, 1993). This also translates into gains in performance, the assumed values of which are also shown in Table 2 (based on the relevant related research reviewed above).

Note that utility analysis provides an estimate of the incremental value associated with a human resource intervention (Sturman, 2003). Thus, for all subsequent analyses, this paper uses matching the market as the point of comparison-so for direct costs, lagging the market saves money, and leading the market costs money.

With the above assumptions, the results of the utility analyses for each of the pay strategies are shown in Table 3. According to these results, the pay policy with the greatest utility is to lead the market by $5 \%$. Because of the value associated with performance and the performance gains achieved through greater compensation, lagging the market by $15 \%$, even with the lowest payroll costs, led to the lowest utility.

\section{Sensitivity Analysis}

The previous analyses suggest that leading the market by $5 \%$ is the optimal pay strategy. Yet, as noted, this answer is predicated on a large number of assumptions. Granted, these assumptions are based on earnest attempts by the owners of Punk's Backyard Grill who have real financial interests at stake with this decision; nonetheless, it is also clear that these assumptions are imperfect at best, and thus a well-implemented utility analysis should also provide information on how sensitive the results are to these estimates. Thus, the utility analysis implementation considers a variety of alternative analyses, with different sets of assumptions, to see how the resultant decision might change. Such sensitivity analyses give the owners some idea of how stable the utility estimates are but, also, where they need to collect data to make better business decisions in the future. In other words, the current solution derived 
from the utility analysis may lead to the initial pay strategy decision (i.e., to lead by $5 \%$ ) and resultant pay levels for new hires; however, through sensitivity analysis, the owners will know what variables are most likely to affect the validity of this solution, and thus can collect this data and update the pay policy incrementally over time.

TABLE 3. Utility Analysis Results

\begin{tabular}{lcccc}
\hline Pay Strategy & $\begin{array}{c}\text { Average } \\
\text { Performance } \\
\text { (in Standardized } \\
\text { Units) }\end{array}$ & $\begin{array}{c}\text { Total } \\
\text { Benefit } \\
(\$)\end{array}$ & $\begin{array}{c}\text { Utility Change } \\
\text { Due to Cost } \\
(\$)\end{array}$ & $\begin{array}{c}\text { Total Utility } \\
(\$)\end{array}$ \\
\hline Lag $-15 \%$ & 0.2590 & 85,577 & $+69,864$ & 155,441 \\
Lag $-10 \%$ & 0.4239 & 140,022 & $+46,576$ & 186,598 \\
Lag $-5 \%$ & 0.5390 & 178,058 & $+23,288$ & 201,346 \\
Match & 0.6299 & 208,093 & 0 & 208,093 \\
Lead $+5 \%$ & 0.7076 & 233,755 & $-23,288$ & 210,467 \\
Lead $+10 \%$ & 0.7778 & 256,941 & $-46,576$ & 210,365 \\
Lead $+15 \%$ & 0.8411 & 277,849 & $-69,846$ & 207,985 \\
\hline
\end{tabular}

A number of parameters were varied, the utility analysis was rerun for each new scenario, and the results were examined to reveal the extent to which the estimates changed. Table 4 presents the sensitivity analysis by presenting the following information: (1) The new "optimal" pay strategy choice given the new scenarios; (2) The estimated effect of selecting the "lead by $5 \%$ strategy" given the revised parameters; (3) The estimated effect of selecting the "match the market strategy" given the revised parameters; and (4) The estimated effect of selecting the "lag the market by $15 \%$ strategy" given the revised parameters. As mentioned earlier, were a decision-maker not to use utility analysis, a highly likely choice would be either to not differentiate the company with regard to pay policy (i.e., match the market), or to make a decision purely based on costs (i.e., lag the market by as much as possible). For the purposes of this paper, the lowest price estimate of lagging by $15 \%$ was used as the comparison point.

As expected, Table 4 shows that changing the assumptions does change the resultant optimal decision. More importantly, the results show where the owners of Punk's Backyard Grill should focus their HR information gathering: on the value of SDy, and on the effects of pay on job incumbents. Varying the assumed $\mathrm{SD}_{\mathrm{y}}$ percents changed the resultant recommended pay decision from lagging by $10 \%$ to leading by $15 \%$. In other words, the more value associated with employees' higher performance, the more value there is associated with investments in those human resources. The results also show 
that the more the pay has a motivating effect on job incumbents, the better the policy to lead the market in pay.

The results also show that, even when parameters are estimated, the results of the initial utility estimate provide more value on average than more intuitive choices. In the eight scenarios, the average loss of sticking with the initial utility estimate would be roughly $\$ 9,340$, whereas it would have been around $\$ 9,600$ for matching the market, and $\$ 57,055$ for lagging the market by $15 \%$. These results clearly show that, unless one truly thinks employee performance is of little value and hence SDy values should be very low, then it is not advisable for the owners of Punk's Backyard Grill to lag the market in pay. However, $\mathrm{SD}_{\mathrm{y}}$ estimates used in these analyses are much lower than previous research estimates have shown them to be in studies on SDy (see Boudreau, 1991), and given the particular emphasis the owners are placing on customer service, it is unlikely that $\mathrm{SD}_{\mathrm{y}}$ estimates will be small.

Certainly, more analyses could be conducted, and one could do endless combinations of sensitivity tests, or even run extensive simulations to vary multiple parameters simultaneously (e.g., Sturman, 2000). This purpose here, however, is to demonstrate a realistic use of utility analysis for helping craft a human resource decision. The fact that the owners found this analysis useful for setting up their pay structure is a critical piece of evidence that utility analysis can aid in decision making.

\section{Conclusion}

Building a compensation strategy for a start-up restaurant is a process that is complex and individualized, dependent on a number of different factors. The industry segment, the overall strategy of the start-up, and the capitalization of the business are all unique factors that must be taken into account when building a compensation plan. Leading the market has some significant benefits, but it is important to fully understand all aspects of the business before making any pay level strategy decisions.

For Punk's Backyard Grill, based upon the emphasis on customer service in the fast-casual segment, the strategy of growth and brand building, and the awareness of the need for additional capital, this start-up should carry out the strategy of leading the market in pay. This strategy will be profitable for the business, will lead to a positive reputation within the industry, and will help prepare the company for growth. Yet the benefits of leading the market must be considered in light of the costs required to achieve them. Factoring together the benefits and costs of leading the market in pay, leading by $5 \%$ seems to be the best recommendation.

It should be noted that the utility analysis required a significant number of assumptions. There simply was no data available on certain aspects of the formula, and thus personal experience was used 
to fill in these gaps. The analyses employed sensitivity analysis to vary some of these key parameters to test the stability of the initial recommendation, but the results are based on estimates nonetheless. While from a research perspective this limits the potential accuracy of the estimate, the reader should recall that the purpose here is to demonstrate how utility analysis can be used to help make a business decision regarding the company's pay strategy. Were cost-benefit analysis not employed, the owners of Punk's Backyard Grill would simply have to use intuition to determine their pay strategy. Certainly, the numbers can be adjusted over time if data are available, or other companies can use their own data (or estimates) when employing the formula, but the primary advantage of this cost-benefit analysis is that it provides at least some quantification of human resource issues so as to assist in decision making. For academics and researchers, it would be desirable to collect more data and validate the utility estimates. For the practitioners like the owners of Punk's Backyard Grill, a pay strategy needs to be determined and other business decisions now need to be made.

\section{References}

Akerlof, G. A. \& Yellen, J. L. (1986). Efficiency Wage Models of the Labor Market. Cambridge: Cambridge University Press.

Anthony, W. P., Perrewe, P. L., \& Kacmar, K. M. (1993). Strategic Human Resource Management. Harcourt Brace Jovanovich (New York, NY: Reed Elsevier PIc).

Boudreau, J. W. (1991). Utility analysis for decisions in human resource management. In M. D. Dunnette \& L. M. Hough (Eds.), Handbook of Industrial and Organizational Psychology, Volume 1, pp. 621745. Palo Alto, CA: Consulting Psychologist Press.

Boudreau, J. W. \& Berger, C. J. (1985). Decision-theoretic utility analysis applied to external employee movement. Journal of Applied Psychology, 70, 581-612.

Brown, M., Sturman, M. C., \& Simmering, M. (2003). Compensation policy and organizational performance: The efficiency, operational, and financial implications of pay levels and pay structure. Academy of Management Journal, 46, 752-762.

Bureau of Labor Statistics (2005). National Compensation Survey: Occupational Wages in the United States, July 2004. September. Bulletin 2576.

Campbell, C. M., III. (1993). Do firms pay efficiency wages? Evidence with data at the firm level. Journal of Labor Economics, 11, 442-470.

Casio, W. F. (2000). Costing Human Resources: The Financial Impact of Behavior in Organizations (4th ed.) Boston, MA: Kent. 
Gerhart, B. \&Milkovich, G. T. (1992). Employee compensation: Research and practice. In M. D. Dunnette (Ed.), Handbook of Industrial and Organizational Psychology, Volume 3, pp. 481-569. Palo Alto, CA: Consulting Psychologists Press.

Heneman, H. \& Judge, T. A. (2000). Compensation attitudes: A review and recommendations for future research. In S. L. Rynes \& B. Gerhart (Eds.), Compensation in Organizations: Progress and Prospects. San Francisco, CA: New Lexington Press.

Hankins, T. R. \& Tracey, J. B. (2000). The cost of turnover. Cornell Hotel and Restaurant Administration Quarterly, 41 (3), $14-21$.

Holzer, H. J. (1990). Wages, employer costs, and employee performance in the firm. Industrial and Labor Relations Review, 43, 147S-164S.

Hunter, J. E. \& Schmidt, F. L. (1982). Fitting people to jobs: The impact of personnel selection on national productivity. In M. D. Dunnette \& E. A. Fleishman (Eds.), Human Performance and Productivity, Volume 1, pp. 233-284. Hillsdale, NJ: Erlbaum.

Klass, B. S. \& McClendon, J. A. (1996). To lead, lag, or match: Estimating the financial impact of pay level policies. Personnel Psychology, 49, 121-141.

Krueger, A. B. (1988). The determinants of queues for federal jobs. Industrial and Labor Relations Review, 41, 567-581.

Maister, D. H. (2001). The path to performance: What managers must do to create a high-achievement culture. Cornell Hotel and Restaurant Administration Quarterly, 42 (6), 90-96.

McDaniel, M. A., Whetzel, D. L., Schmidt, F. L., \& Maurer, S. D. (1994). The validity of employment interviews: A comprehensive review and meta-analysis. Journal of Applied Psychology, 79, 599616.

Milkovich, G. T. \& Newman, J. M. (2005). Compensation (8th ed.) New York, NY: McGraw-Hill.

Peterson, S. J. \& Luthans, F. (2006). The impact of financial and nonfinancial incentives on business-unit outcomes over time. Journal of Applied Psychology, 91, 156-165.

Rynes, S. L. \& Barber, A. E. (1990). Applicant attraction strategies: An organizational perspective. Academy of Management Review, 15, 268-310.

Schmidt, F. L., Hunter, J. E., Outerbridge, A. N., \& Trattner, M. H. (1986). The economic impact of job selection methods on size, productivity, and payroll costs of the federal workforce: Test of three hypotheses. Personnel Psychology, 39, 1-29. 
Sturman, M. C. (2003). Introducing utility analysis for hospitality: A tool for quantifying the value of human resource interventions. Cornell Hotel and Restaurant Administration Quarterly, 44 (2), 106-116.

Sturman, M. C. (2001). The compensation conundrum. Does the hospitality industry shortchange its employees-and itself? Cornell Hotel and Restaurant Administration Quarterly, 42 (4), 70-76.

Sturman, M. C. (2000). Implications of utility analysis adjustments for estimates of human resource intervention value. Journal of Management, 26, 281-299.

Sturman, M. C., Trevor, C. O., Boudreau, J. W., \& Gerhart, B. (2003). Is it worth it to win the talent war? Evaluating the utility of performance-based pay. Personnel Psychology, 56, 997-1035.

Taylor, P. \& Small, B. (2002). Asking applicants what they would do versus what they did do: A metaanalytic comparison of situational and past behavior employment interview questions. Journal of Occupational and Organizational Psychology, 75, 277-294.

WageWatch (2006). WageWatch [web-based computer software]. Available at http://www.wagewatch.com.

Williams, K. (2001). Competitive compensation will attract employees, but strong leaders retain them. Nation's Restaurant News, Jan 15, 35 (3), 34-64.

Williams, M. L. \& Dreher, G. F. (1992). Compensation system attributes and applicant pool characteristics. Academy of Management Journal, 35, 571-595. 